\title{
The meander: A narrative inquiry into a foreigner who became a Filipino
}

Cuyacot, Eljim P.

NYC Department of Education, USA (ecuyacot@gmail.com)

Cuyacot, Marilo T.

NYC Department of Education, USA (mcuyacot@bronxinternationalhs.com)

Deligero, Jilliane A.

University of the Visayas, Philippines (jillianedeligero@gmail.com)

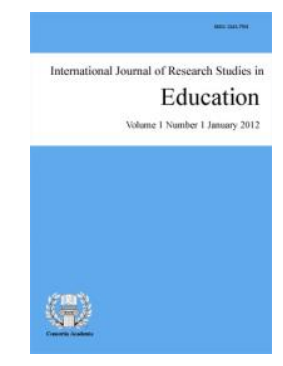

ISSN: 2243-7703 Online ISSN: 2243-7711

OPEN ACCESS

Gaje Jr., Jose M.

University of the Visayas, Philippines (josemgajejr@gmail.com)

Gitgano, Rubilyn

NYC Department of Education, USA (rubgit@ gmail.com)

Magpatoc, Argie G.

University of the Visayas, Philippines (aremheck@gmail.com)

Malasarte, Leslie

NYC Department of Education,USA (Scienceps66@gmail.com)

Received: 30 January 2022

\section{Abstract}

The narrative illustrated the resilience of a young foreigner sent by his parents to the Philippines to seek refuge during the civil war that broke out in his native land who eventually became a famous YouTube vlogger and content creator. Narrative inquiry was used to describe the past experiences of Bae, also known as The Meander, who came to the Philippines as a teenager alone. It explored Bae's journey away from his family in a foreign land. Additionally, it revealed how he handled the challenges without even knowing how to speak Filipino or English. A qualitative analysis of the in-depth interview with Bae on YouTube revealed that he struggled from the minute he set foot on Philippine soil. His struggles included, among others, feelings of loneliness and isolation, adapting to Filipino culture, financial struggles, and how he became a citizen of the Philippines. As a consequence, Bae's story provided specific insights to people who may face a similar situation.

Keywords: narrative, meander, citizen, vlogger, loneliness, isolation, financial 


\section{The meander: A narrative inquiry into a foreigner who became a Filipino}

\section{Introduction}

This narrative inquiry concerns the Meander, age 18, named Bae. In 2013, his parents sent him to the Philippines during the outbreak of the civil war in their native land. The narrative of the story was adapted from an interview with Bae conducted by a YouTube vlogger. In this story, Bae recounts how he survived living alone and away from his family. Bae's story is an inspiration to those who have gone through similar experiences. His story illustrates his resilience in the face of the challenges and difficulties of being a foreigner in a foreign land. In this narrative, he described how he overcame challenges and turned them into motivation to become a Filipino citizen. Researchers were drawn to the story due to its uniqueness given that he was sent alone to a foreign land. $\mathrm{He}$ is now one of the most influential YouTube vloggers under the pseudonym "The Meander". The use of narrative inquiry as a research design involves using stories as data and as a method to understand people's experiences. It presents a chronological account of an individual's experiences, based on their personal, social, and historical context, and it incorporates the significant themes of those lived experiences (Creswell, 2013). It is argued by those who use this design that stories are the closest thing to a shared experience. In this study, we examined the challenges faced by a young migrant forced to move to a foreign country. Specifically, we investigated how the young man managed to adjust to the situation. Researchers hope that others in a similar predicament can learn from this study.

\subsection{Objectives of the Study}

This study was conducted to examine and write the details of the past experiences of a young Meander who lived and studied in the Philippines. His story was shared through an interview online and expected to help people understand the reasons why foreigners wanted to become a Filipino citizen. It investigated how the participant managed to overcome the challenges of living alone away from his parents and siblings at a young age.

\section{Methodology}

Qualitative research allows for simultaneous collection and analysis of data (Creswell, 2003). As a result, data analysis began immediately after watching the interview and continued throughout transcription. Bruner (1986) described two types of cognition in narrative inquiry, specifically, the paradigmatic and narrative inquiry methods. Polkinghorne (1988) defined the former as the telling of stories as a "virtually uninterrupted monologue", while Bruner defined it as the recognition of elements as members of a category. However, the latter combines elements into a story with plots (Bruner, 1989) and provides meaningful structures through which to organize incoherent data components (Dole, 2001). The narrative analysis concept of Bruner (1986), which was further developed by Polkinghore (1988), provided the opportunity to move from analysis to storytelling, since Gergen and Gergen (1986) suggest that this is "perhaps the most essential ingredient of a narrative accounting (or storytelling), [that] is, its capability to structure events in such a way that they demonstrate, first, a connectedness or coherence, and second, a sense of movement or direction through time". Further, Polkinghore (1988) also argued that the story "must fit the data while at the same time bringing an order and meaningfulness that is not apparent in the data themselves". A combination of these two methods was used in analyzing the data.

While transcribing the one-on-one interview, the researchers were able to immerse themselves in the data (Ching, 2021; Teng, 2020; Riessman, 2005). Having read the transcriptions of recorded interviews, we listened and watched the video interview repeatedly in order to understand the emotions and it is important to include both words and specific features (crying, long pauses, laughter). 
The text that was used in this study was an in-depth semi-structured interview conducted by a vlogger in her YouTube Vlog. During the interview, Bae answered several open-ended questions, especially about his experiences as a foreigner living in the Philippines away from his family. Some of his stories were also clarified with the help of follow-up questions. The interview lasted about 25 minutes. The video was played multiple times; the narratives were carefully transcribed. After reading the transcription several times, different themes emerged. These themes were indexed with various highlighted colors and with notes in the margin. The themes were organized into diagrams to explore possible links among them. An initial story was then drafted from these organized themes. One limitation of the study is that there is no possibility of collaborating with the participant. In order to ensure the accuracy of the transcription, several members of the research team watched the video and read the initial story. Three other researchers were asked to listen again to the interview and confirm our coding themes. Some corrections from the researchers' review were incorporated to create the final story. And as part of our data analysis, we used the paradigmatic-type of inquiry method.

\section{Bae's Story}

As a result of the Civil War in the Meander's homeland in 2013, Bae's family decided to send him to the Philippines. Out of safety, his family sent him to the Philippines to study English. During that time, he was between 18 and 19 years old and his very first time away from his parents. Currently, his family lives in different places; his father lives in France and his mother and sister live in Saudi Arabia. They have unique ways of living their lives separately as he lives in the Philippines. Since he last saw them nine years ago, he definitely misses his family.

It was completely unknown to him that he would be going to the Philippines. Both his parents traveled abroad but not him. Despite his adolescence, he is a certified mama's boy. Upon telling him he could come to the Philippines, and giving him a visa, came as a surprise to him. He lashed out, protesting that he had no choice but to live his life unaccompanied. His father drove him to the airport while his mother cried, and they hadn't seen each other since exactly nine years ago. He kept in touch with them by video chatting on social media.

It was an unfortunate reality for him that his family was not able to attend his graduation. They attended it via video call; he bought a coat and went to PICC on his own. They still find it hard to believe that he graduated. Although he lived away from his family, he was able to overcome his challenges with grace and success. For instance, he knew nothing about household chores like frying eggs. However, he had no choice. The six months leading up to his departure to the Philippines were difficult for him, as he spent virtually every day crying. The six months were tough. Culture shock had taken hold of him.

He was so shocked by the experience that he stopped eating. It is a known fact that he did not usually eat Filipino food, as he preferred sandwiches. He became aware that Filipinos prefer rice overwhelmingly to anything else. Having been fed rice by Filipinos, he has adopted it and will not eat without it. According to him, rice (kanin) is life, so he adopted it. Aside from that, he did not know what meat was pork and what was not. Due to his poor English, he is unable to figure out which food to order or how to order it. He later began purchasing soft drinks and biscuits from a sari-sari store where he could get a part of his daily meal. His family was unaware that he lost almost $15 \mathrm{~kg}$ of body weight. After losing weight, he decided to experiment with Filipino foods. First, he tried Tinolang Manok, which he liked very much. After trying it, he was hooked. Some people might say that chicken adobo is good, but he felt it was the best. Since then, he has begun to explore more and more Filipino food. Eating isaw sounded tempting, but he was scared after finding something gross inside. He says the weirdest Filipino food he tried was not balut, but fishballs and kwek-kwek.

Nobody is willing to assist him in learning English as he decides to do so. Google showed him a list of English-language schools in Makati, so he started looking. Another challenge is how he will travel to Makati since he lived in the south, he is unfamiliar with transportation. He was overwhelmed by the number of schools in Makati when he arrived there. For hours, he wandered around Makati in search of the school without success. 
Then he decided to purchase internet data and type in the address. It took him three months to learn English. At that point, he was able to interact with others and gradually began to feel comfortable. In his opinion, being able to speak is a key to interacting, understanding, and communicating with others.

That was the time he decided to start formal schooling. His family supported him financially while he was away from home. Although his father did not come from an affluent family, he was an accomplished engineer and worked for the government. Therefore, rather than giving him a regular allowance, his family sent him whatever money he needed. But he didn't ask for anything from his family. Whenever his family gives him money, he tells them that is enough. He wanted to be that way. Thus, instead of completing the course in five years, he finished the course in four years. He was highly motivated because he hoped to graduate in five years or less.

He also does not intend to be a vlogger in the Philippines. He accidentally became one. Occasionally he traveled during the summer while he was still studying. While he was traveling, he took videos of the surroundings. The beauty of the Philippines blew him away when he visited Boracay, Palawan, and anywhere else around the country. This is a country he has no idea how breathtaking it is. It was obvious to him that many rich middle easterners don't know how beautiful the Philippines are. His goal was to spread the word about it. When he traveled, he only took videos of his surroundings and wasn't vlogging at the time. He then shared it with his family and friends back in his hometown. He would like to tell them that he traveled through these parts. His family and friends were envious of his travels. He found the Philippines to be a beautiful place and became infatuated with it. He visited El Nido and Coron in Palawan in the Philippines, which he thought were beautiful places. It wasn't until he started uploading his videos and footage to YouTube that he realized he could showcase and share it to a lot of people without even considering vlogging. Uploading videos was just something he did whenever he had one. The article reached a wide audience, including his family, and when they saw the Philippines' beauty they were shocked, as many middle easterners are unaware of what the Philippines have to offer. The OFWs in his country were the only reason why Filipinos were known for their hard work. Then and there, he wanted to be the instrument for showing the world the beautiful places he visited, but he didn't realize how many people were going to enjoy it until they subscribed to his YouTube channel. As a result, he was surprised that he gained so many supporters and was not expecting this to happen.

It was his goal to graduate and do something after graduation, preferably land a good job. Afterwards, he wanted to help Filipinos by giving them jobs.

In addition to believing in good Karma, he has also learned to help people in need whenever possible as part of his family's values. It is well known that his father is a good Samaritan and an especially generous man. The same is true for his mother. Regardless of his religion, his belief in good karma encouraged him to give clothes, food, and the like to others in the community. According to him, what goes around comes around. If you do good for others, good will certainly follow. Due to his love of food and desire to help people on the street, he became like a Filipino unintentionally. Filipino culture has already captured his heart. His behavior already mirrors that of a Filipino. It reflects the way he lives. It's more natural for him to become a Filipino, even if he doesn't intend to do so. In their homeland, in their culture, if they deny their origin and no longer regard themselves as loyal, they will be considered persona non grata. The Philippines seems to have captured his heart and he decided to live there. After completing his studies, he was offered to go and live with his father and brother in France. It is likely he will get an immediate job there since his brother has good connections there. Due to his desire to earn his own money, he declined the offer. This led him to make a difficult decision. Having grit and passion to succeed for himself, he started to apply for jobs not for his family's benefit, but because he wanted to help himself. Since he wanted to be a mature adult, he didn't want to ask his family for money for an allowance. Despite his repeated attempts to land a job, he wasn't successful due to the fact that he is not a Filipino citizen.

As a sideline and part-time job, he decided to become a translator. He translates Arabic into English or Filipino, and the other way around. His sister paid for such a luxurious Alabang condo for him, so he started 
moving out of the condo. By 2017, he was living in a small apartment in the south. It wasn't the best. From there, he went independent. Sometimes, he ran out of money, but he never asked his sister.

For him, becoming a Filipino citizen is an amazing experience. This made him feel good because he doesn't feel like a foreigner. Whenever he stopped somewhere, he spoke Tagalog even though Filipinos were laughing at him for doing so and giving him compliments like "Ah marunong ka pala" (Oh! You know Tagalog). During his interview with a vlogger, he was asked in Tagalog, "Anong nararamdaman mo ngayon?" (how are you feeling right now?). He uttered "Masaya" (happy). Having been with Filipino people made him feel happy, he added gratefully. Filipinas are cute to him, he added. He found them cute since he is used to being surrounded by tall people, such as his sisters, who are 6'5 and 6' 1 respectively. The reason he liked cute women was that they were easy to hug and carry. His favorite features are women's lips, mouths, eyes, and faces. According to him, Filipinas are caring and supportive. Whenever someone is sick, they have medicine at their disposal.

In his view, the Philippines is his home not because of his life here. With over 40 employees working for him, he created jobs for Filipinos in this country. At the moment, he is working on a big project that will provide employment to many Filipinos. He will offer a great opportunity to the Filipino community, which will leave a lasting impact on them. Through his work, he provided them with a stable job. In the same way as the Filipinos, he wanted them not to be picky. Having worked as a kargador (hard labor) in the morning, a cashier in the afternoon, and a YouTuber at night. It was not an easy life. In the Philippines, all of his experiences were the product of his perseverance and determination, and he also wished to convey this to his employees. He would not be who he is today had it not been for his experiences in the Philippines. Realizing the need for personal support, he turns to the people around him. He experienced this at many points during his time as a student. He was desperate to talk to his family even via phone call, but he was unable to do so. Knowing the difficulties, he encountered alone and the pressure he encountered, he believes that only a few foreigners could do the same.

Furthermore, his main and vital goal is to be able to make a positive impact on a lot of people's lives. Over the past two years, he hired people for his company. People knew that if he went big, they too would. It provided them with opportunities. The employees have nothing but him so he could not just leave them behind, so he worked hard to grow the company to the benefit of everyone. He is already nearing the realization of his dream. Follow the waves wherever it takes him, especially on helping people to live their dreams as well. Follow the waves wherever it takes him, not driving a Ferrari. Choosing simplicity is his favorite way of living. Eventually, he plans to remain in the Philippines. As he feels the Philippines is his home, he has chosen to stay in the country. No matter what his nationality was, he felt at home. He certainly adapted to the environment. He was used to the Philippines' way of life. In his opinion, the people in the Philippines are very different from those elsewhere.

Even though he simply followed what his parents wanted him to do, he walked around Makati thinking, whatever happens, he will continue to walk proudly wherever his feet may bring him success. Then, now he can see that success means being with the people you love most (except family) and happy to be of service to them is fulfilling. According to him, the best part of Filipinos is their crazy nature, but in a positive way. As he walked down the street, Filipinos wanted to shout at him. Generally, Filipinos are friendly and playful. He enjoys being around Filipinos. He thinks they have the best personalities.

\section{Results}

There were several themes discussed in Bae's Narrative. Specifically, five themes were developed: Feelings of Loneliness and Isolation, adapting to the Culture, Financial Difficulty and Stability, Giving Back and Becoming a Filipino. In some instances, direct quotes of the participant are reported, except in making tense corrections.

\subsection{Feelings of Loneliness and Isolation}

Bae narrated that he was separated from his family when he was just 18 years old. This was during the 
outbreak of his homeland's Civil War in 2013. His family sent him to the Philippines for safety reasons while studying and learning English. It happened so quickly that when he got his visa, the following day he was already in the airport. He didn't even know where the Philippines was located. This is how he described the day he was separated from his family and his feeling of isolation.

It was the first time being separated from my family. Currently, my family lives in different places. My dad and brother lived in France, my mom and sister in Saudi Arabia and I live in the Philippines. The last time I saw them was nine years ago. I do miss my family. There is no way I can tell you where the Philippines is. As a child, I did not travel abroad with my parents but they did. Growing up, I was a mama's boy. They just told me you're going to the Philippines. Here is your visa.

Bae further added that he did not like the idea of living alone by himself. He narrated his feeling of being lonely and having not seen his parents and siblings in person. Bae shared,

I cried. At first I objected. I said I couldn't live by myself. My father drove me to the airport. When I left, my mom was crying. That was nine years ago. We have not seen each other again.

Bae further expressed the desire to have someone to be around, especially when he experienced the pressure and hardship. He narrated the challenges of being away from the family and knowing nothing about anything.

As it was my first time leaving my family, even the simple act of frying eggs was completely new to me. The first six months were very challenging. I cried almost every day. I requested that they book me back. It was hard. I don't think everybody will take what I took. The pressure and hardship. It's not easy at all. You're all by yourself. The reality kicks in when you feel that you need at least to talk to your family. And it happened to me many times before when I was a student. Even when I tried to call them I couldn't reach their phone so I was really alone.

Bae added that he will only talk to his parents and siblings through video calls. He said that "I had them attend my graduation via video call." No one from his family was able to attend his graduation in person. It was really a difficult experience for him. But despite being alone he was able to finish his studies and graduated.

\subsection{Adapting the Culture}

Bae shared that he experienced culture shock. He explained the disparity between his culture and that of the Philippines. When asked what shocked him about the culture. He replied,

I'm not used to Filipino food. Bread and sandwiches are what I'm used to. Here it's all about rice. "Kanin" or rice is life. That's what has happened to me now. You must always give me rice. I don't eat without rice. I got culture shock to the point that I stopped eating. Also, I don't eat pork. When I go outside, I don't know which meat is pork or not. In addition, my English was not good. I have no idea what I am ordering and getting. Then I started going to a sari-sari store to buy soft drinks and biscuits. That was my meal for the day. My family did not know about it. I lost like 15 kilos of my weight.

The fact that he settled on eating soft drinks and biscuits is hard to deal with but out of perseverance he stood still. He learned to eat Filipino foods later on as he stated:

The first Filipino dish that I tried is tinolang manok. I love it. It was my number one. Some people say chicken adobo, they are wrong. Ever since I started exploring more, more and more Filipino foods. I was about to try chicken isao but I got scared one time because I found "dumi" sa loob. The weirdest thing I tried in Filipino food is not Balut. I don't eat them. It's fishball and kwikwik.

48 Consortia Academia Publishing (A partner of Network of Professional Researchers and Educators) 
Bae also described how difficult it was for him to communicate with people. He mentioned how he struggled to learn the English language as he narrated:

\begin{abstract}
As I began to learn English, no one helped me. I looked up English schools on Google. Because I lived in the south, the school which popped out is in Makati. I am from the south and am unfamiliar with transportation. I did not know how I reached the school until now. In Makati, I roamed around for hours looking for the school. I just have the address stored on my phone. For three months, I studied English. Because I was able to communicate with others, I began feeling comfortable. With the ability to speak, one can interact, understand, and communicate with others. That was the time I started school.
\end{abstract}

His determination and perseverance to learn how to speak English gave him confidence and made him feel comfortable. These experiences helped him a lot in appreciating life and culture in the Philippines.

\title{
4.3 Financial Difficulty and Stability
}

While studying, Bae described how his family supports him financially. Without asking for more, he explained how he budgeted the money sent to him by his family. According to Bae:

I have been supported by my family. I come from a well-off family back in my country. My father was a highly respected engineer. Previously, he worked for the government. But I'm not the type of person who depends on family. I don't ask for anything from them. My family should send me whatever money I need rather than sending me whatever allowance I want. I always tell them that whatever you give me is enough. That's not the kind of person I want to be. It is for this reason that my graduation was not delayed. The course I'm taking is five years long. In four years, I completed it. My goal was to graduate on time. I was really focused.

Bae said that he wanted to become independent and was looking for a job to earn a living after graduation. He mentioned the difficulty of getting a job because of being a foreigner. He further added:

I started applying for jobs not because my family expected me to work or because I needed a job, but because I wanted to be independent. I don't want to ask for money or allowance from my family. I want to become a grown up man. I tried to find a job, but was turned down because I am not a Filipino citizen. I was doing sidelines. Like translation because I speak Arabic, English and a little bit of Tagalog. So I do freelance work.

He described how he started living using his own resources and no longer depended on his parents and siblings. He added that he moved from a luxurious apartment to a small one. In the interview he said:

I moved out of my condo because my sister was the one paying for a luxurious condo for me in Alabang. I moved out and I lived in a small apartment in the south in 2017. Not a good one hahaha. He said jokingly. I started becoming independent. I ran out of money but I never asked my sister.

He narrated how he became a vlogger and it became a source of a living. He added that it was not his intention to become a vlogger. He said he had no idea at the beginning that what he was doing would make him who he is right now in the world of vlogging. He added that he was just taking pictures and videos of the places he visited and sharing them with his family and friends. He described his amazement and appreciation of the natural beauty of the Philippines. In his words he said:

When I was still studying, I used to travel occasionally. During the summer or something like that. I take videos of my surroundings when I travel. I show the places I visit. I go to Boracay, Palawan and anywhere around the country. I was actually blown away by the beauty of the 
Philippines since I had no idea how gorgeous the country is before coming here. Honestly, most middle easterners have no idea how beautiful our country is. The Philippines has a beautiful side that many rich middle easterners do not know. I saw it myself. When I saw it, I wanted to show it to other people. I was not vlogging at the time, I was only taking videos of my surroundings when I was traveling. Then, I began sharing it with my family and friends in my homeland. I told them I had been to these beautiful places. Having traveled through this region, I would like to let them know. It's really nice here. I started falling in love with the Island.

Bae showed excitement in the interview about his experience and what he saw in the places he visited. He added that the most beautiful places that he visited in the Philippines were El Nido and Coron in Palawan. He told in the interview how he started uploading videos on YouTube.

So I discovered that I could upload the videos on youtube. I can show it to more people and share it with more people. So I started uploading on youtube but I was not vlogging because I was still a student then. I just upload whenever I have a video.

In the interview, Bae was really surprised how people appreciate and like what he is doing. He added, "I didn't expect it. I mean this because I was not really planning for this. I just have a dream to graduate and do something after graduation. "Bae explained that through his uploads, he wanted to show people the beauty of the Philippines that many rich middle easterners didn't know about.

Many of the people, including my family, were shocked by what they saw. It is because not many middle easterners know much about the Philippines. They only knew we had a lot of OFWs who are Filipinos and really worked hard. I wanted to be the means to show the beautiful places I go to. I didn't know that people would like what I was doing. People started supporting me. More people even like the idea and like my video. They are asking me to upload more videos.

Bae was shocked that his followers started growing. Currently, he has about 4.47 million followers and has uploaded more than 550 videos on YouTube. This opportunity gives him the financial stability to support himself as well as the people that worked for him.

\subsection{Giving Back}

When asked about when he started giving back, Bae explained that it comes from his family values. He recounts that his family believed in good karma. He narrated:

When I was growing up, my family had values. We believe in good Karma. Back home, my dad is known for that. He is a very generous person. As well as my mother. In my home country, we were like that. The belief in good Karma led to it. In our family, we always give away clothes, food, and other things because we believe in good karma. It doesn't matter what religion you follow. It's just that as you do good, good things come back to you.

He added that because of his hard work and determination, he is able to help many Filipinos.

Not only that I have a life here, I mean I created many jobs for many Filipinos. As of this moment, I have like 40 employees working for me. I'm currently working on a big project that will employ a lot of Filipinos. If it succeeds with me, it's going to be a big opportunity. It will have an impact on people if I'm able to provide jobs even for 40 people. At least I'm able to give them stable jobs. They go to work. I just want to tell you; you might see me anywhere. I could be a "kargador" in the morning, a youtuber in the evening. I could be a cashier in the afternoon. You see me all over the place and you'll be shocked because sometimes you might see me carrying boxes or not. So I work hard.

50 Consortia Academia Publishing (A partner of Network of Professional Researchers and Educators) 
He stated that "I wanted to feel good about myself. And that's the reason why I decided to come up with something to do with my own labor and my own work." He expressed with conviction the best thing that happened in his life. He narrates

Best thing about my life right now is that I'm able to change the lives of many people. I have people who have worked for me for like 2 years and they know already if I go big, they go big. We go all together. So I'm giving them chances in life. They have nothing but my side. So I'm not just letting them go. I told them you know if we get big you're gonna be with me.

\subsection{Becoming a Filipino}

When asked why he loved the Philippines, he clarified about his being a true blooded Syrian, however he stated that it was his choice to become a Filipino citizen without disowning his citizenship. Bae relates it this way.

First of all I will not deny the fact that I'm a full blooded foreigner. If you deny your origin, you are no longer loyal. And I fell in love with the Philippines. I chose to live here. After graduation, I was offered to go to France and live with my father and brother. I was offered an instant job because my brother has connections there. It was because of a desire to earn my own money that I refused. It was a tough decision for me to make. Unintentionally, I became like a Filipino because I love food. I already love the culture. I already act like one. I lived like one. So it's not that I intended to, like I want to be a Filipino or I want to be whatever. It just came naturally.

For Bae, becoming a Filipino made him feel good. He said, "It's amazing of course. It's good. I mean for me; I don't feel that I am a foreigner. Until now, if I stop somewhere and I speak Tagalog, they laugh at me. They would say, "Ah marunong ka pala." He loved that people acknowledged him learning to speak Tagalog. When the host requested him to respond in Tagalog, he said, "let's try it." He was asked, "Anong nararamdaman mo ngayon?" He replied, "happy." The host laughedly replied, "that's in English." He replied, "masaya" which means "happy". He continued, "Masaya ako kasi kasama kayo." In the interview he claimed, "This is where I feel at home." When he was asked how long he would stay in the Philippines, he replied, "I think for good." Bae added:

I feel like this is my home. This is where I belong. Even though whatever nationality you have, you will adapt. So this is what happened to me. I adapted to the lifestyle here. The "Mga Tao" or "The People" here, they're different from the "Mga Tao" in France than wherever you go. Mga Tao here, they're crazy. Some of them shout at me when they see me in the street. "Mga Tao". I like that. They're not like the type of Mga Tao in France. They are friendly. And I love them. So "Mga Tao" here is the best "Mga Tao".

When asked about his dreams now, he said, "My dream is already happening." He said that his dream is not driving luxurious cars. He added that, "I like to live simple, I like simplicity of life." In the interview he concluded," I love the Mga Tao here."

\section{Discussion}

It is always a challenge to live in another country. Bae's personal development was influenced significantly by living in the Philippines - in a foreign language and culture. There is nothing wrong with the change. Nevertheless, this paper refutes the claim that one may completely forget the social conditions of their home country by permanently living in another country. In this story Bae categorically mentioned that he will never forget that he is from a foreign country. Although the change is never permanent, it is only oriented towards the desire that drove one into another country. From the Meander's tale, we can derive the following key points. 


\subsection{Acculturation}

Throughout his cultural contact and exchange, Bae adopted specific values, traditions, ideas, beliefs and practices that were not originally his own, which one way or another changed his thinking process and caused him to make a conscious decision to engage in certain cultural practices. An experience like living in a foreign country can be extraordinary, but it can also have profound effects on your life. You need to be resilient in every challenge you encounter. Nevertheless, if you already understand the norms, then you will be compelled to embrace them and integrate them into your life. In similar fashion to Bae, he both preserved his original culture and adopted a new one. This is known as integration by code-switching or bicultural. Acculturation occurs when Bae misses home, considers his regular life away from home, and is comfortable remaining in the adopted environment. It's learning how to accept another type of society and culture into your daily life. Since you are living in a place with different customs and traditions from yours, you have to be able to develop yourself in unknown conditions. Embrace new friendships, learn about different viewpoints, accept different opinions and values, and take advantage of every opportunity to travel. Therefore, you will gain true knowledge and a new set of experiences.

\subsection{Personal Independence or Self-Reliance}

The most significant effect of living away from home is the independent behavior that grows inside. You acquire a good and strong sense of responsibility by living apart from your family and earning out a living on your own. Being independent and responsible in life will enable you to accomplish every goal you desire. As we see in the Meander story, Bae's inner confidence shines through, he's being decisive even when he doesn't know how to speak English or Tagalog, and he recognized his own self-reliance not to let external factors dictate his happiness. By establishing honest relationships, he was able to earn without conforming to social expectations. Essentially, if you are in a foreign country, following your own ideas of truth, rather than relying on and following the ideas of others, will greatly improve your life.

\subsection{Coping Strategies}

In this story, Bae used a variety of coping strategies to manage the pain of being alone and separated from his parents and siblings. One strategy that he used was adaptive coping strategy. Bae narrated that he lost almost 15 kilograms of his weight because he is not used to eating Filipino foods. More so, that he has language difficulties in communicating what he wants to say. Losing weight made him realize that he needs to do something. This enabled him to try eating Filipino food. He managed to adjust and eventually adapt to the reality where is in. He confronted the problem head on in order to survive. Now, he can't anymore eat without rice. He even said that rice is life.

Acceptance was another coping strategy Bae used. It's an acknowledgement that something is as it is. It has happened and we cannot change it. He realized he must accept the circumstances as they are. Having to live his life is what he must do. Bae was able to prevent the strong pain of isolation from escalating to suffering by using this strategy. Despite all the struggles and challenges, Bae has overcome them because he avoids dwelling on feelings of loneliness and isolation. This method is referred to as avoidance coping. It is a maladaptive form of coping in which one changes their behavior to avoid thinking about, feeling, or doing difficult things. In this way, he was able to do his normal daily activities. Despite the fact that he has a lot on his plate, he managed to be on top of everything because he was focused on being successful at what he is doing.

\subsection{Social Responsibility}

A rewarding aspect of this story is that it advocates supporting social issues like unemployment. As part of his attempt to assist the "Mga Tao," Bae created his vlog and other small businesses that would give them work. In order to be successful in all activities he is involved in, he needs to build public trust as well as improve the 
environment he is in. In addition to providing work for the Filipinos, he also wishes to enhance positive relationships and improve the lives of the "Mga Tao" as his way of thanking them for their kindness. According to Bae, determination, hard work, loyalty, closeness, togetherness, and honesty will lead to good karma. Therefore, he wanted to show his gratitude to the people who welcomed him. Having done so, he understood that doing good deeds would bring prosperity, personal growth, and increased profits to him, as well as to the country and its citizens. Social responsibility is sometimes viewed as a positioning theory in which values, influences and ways of change may construct relationships and social representations.

\section{Conclusion}

We conducted this study to investigate and understand the experiences and perspectives of a young Meander, Bae, who lived and studied in the Philippines. His story revealed how he struggled living alone and away from his parents and siblings. It highlighted his feelings of loneliness and isolation, financial struggles and difficulty in adjusting to Filipino culture. It further revealed that he was able to overcome all these challenges because of his resiliency, will and determination. He was determined to reach his goal to become independent. Living in the Philippines eventually made him feel and act like a Filipino. Being immersed in Filipino culture made him realize how much he is already a part of it. We are reminded by this story that you don't have to be Filipino by blood to be Filipino. From his experiences, it is clear that Bae is a Filipino more than a natural born citizen. He loves being a Filipino and the "Mga Tao".

\section{References}

Boyes, A. (2013). Avoidance coping: Avoidance coping plays an important role in common psychological problems. Retrieved from https://www.psychologytoday.com/us/blog/in-practice/201305/avoidance-coping

Bruner, J. (1986). Actual minds, possible words. Cambridge, MA: Harvard University Press.

Ching, G. S. (2021). Academic identity and communities of practice: Narratives of social science academics' career decisions in Taiwan. Education Sciences, 11(8), 388.

Creswell, J. W. (2003). Research design: Qualitative, quantitative, and mixed method approaches (2nd ed.). Thousand Oaks, CA: Sage.

Creswell, J. W. (2009). Research design qualitative, quantitative, and mixed methods approaches (3rd ed.). SAGE publications.

Cun, A. (1970). Learning about the stories of children with refugee backgrounds through the lens of positioning theory: Semantic scholar. Retrieved from https://www.semanticscholar.org/paper/Learning-About-the-Stories-of-Children-With-Refugee-Cun/9e6 b0d39503e357d0d86cdb7833ee5aa3c0fee07

Gergen, K. J., \& Gergen, M. M. (1986). Narrative form and the construction of psychological science. In Sarbin, T. R. (Ed.). Narrative psychology: The storied nature of human conduct (pp. 22-44). New York, NY: Praeger.

Gonzaga, T. (2021). Why Basel chose to Become a Filipino| Toni Talks. YouTube. https://www.youtube.com/watch?v=M0mxNVmlcoo

Han, L., Berry, J. W., \& Zheng, Y. (2016). The relationship of acculturation strategies to resilience: The moderating impact of social support among Qiang ethnicity following the 2008 Chinese earthquake. PloS one. Retrieved from https://www.ncbi.nlm.nih.gov/pmc/articles/PMC5065190/

Katalinic, N. (2015). Acceptance a new way of coping. http://www.thinkclinicalpsychologists.com.au/2015/10/26/acceptance-a-new-way-of-coping/

Luo, M., Zhang, X., Peng, F., Zhao, J., \& Deng, H. (2021). Predictors of acculturation attitude of international students in China. PloS one. Retrieved from https://www.ncbi.nlm.nih.gov/pmc/articles/PMC8631655/

Mak, J., Zimmerman, C., \& Roberts, B. Coping with migration-related stressors - a qualitative study of Nepali male labour migrants. BMC Public Health, 21, 1131. https://doi.org/10.1186/s12889-021-11192-y 
Cuyacot, E. P., Cuyacot, M. T., Deligero, J. A., Gaje Jr., J. M., Gitgano, R., Magpatoc, A. G., \& Malasarte, L.

Mishler, E. G. (1986). Research interviewing: Context and narrative. Cambridge, MA: Harvard University Press. Re, T. S., Bragazzi, N. L., Siri, A., Cisneros Puebla, C., Friese, S., Simões, M., Candau, J., \& Khabbache, H.

(2017). Effects of acculturation, coping strategies, locus of control, and self-efficacy on chronic pain: study of Chinese immigrant women in Italy - insights from a thematic field analysis. J Pain Res., 10, 1383-1390. https://doi.org/10.2147/JPR.S115449

Riessman, C. K. (2005). Narrative analysis. In N. Kelly, C. Horrocks, K. Milnes, B. Roberts, \& D. Robinson (Eds.), Narrative, memory and everyday life (pp. 1-7). University of Huddersfield.

Scott, E. (2021). Avoidance coping and why it creates additional stress. https://www.verywellmind.com/avoidance-coping-and-stress-4137836\#: :text=Procrastination\%2C\%2 0passive\%2Daggressiveness \%2C\%20and,are\%20forms\%20of\%20avoidance\%20coping.

Sutton, J. (2022). Maladaptive Coping: 15 Examples \& How to Break the Cycle. https://positivepsychology.com/maladaptive-coping/

Teng, F. (2020). A narrative inquiry of identity construction in academic communities of practice: Voices from a Chinese doctoral student in Hong Kong. Pedagogies: An International Journal, 15(1), 40-59. 